\title{
Cloud Computing Adoption at Higher Educational Institutions in the KSA for Sustainable Development
}

\author{
Ashraf Ali \\ Department of Computer Science and Information \\ College of Science Al Zulfi, Majmaah University \\ Kingdom of Saudi Arabia
}

\begin{abstract}
Rapid changes in the advancements of information and communication technologies (ICT) have prompted Higher Educational Institutions (HEIs) to enhance teaching and learning. Over the years, cloud computing (CC) has become an emerging and adoptable paradigm in many industries including healthcare, finance, and law with its promising benefits. This trend is also growing in the field of education around the globe. Due to its inherent qualities of reliability, scalability, flexibility and reasonable cost, cloud is the solution that addressed the accessibility issue for quality education. CC plays an important role and will have major impacts on HEIs of the Kingdom of Saudi Arabia (KSA) in the near future. HEIs are used to utilize the benefits of $\mathrm{CC}$ based services provided by the cloud service providers (CSPs). The CSP can be owned by the KSA government, private, or third-party vendors. By using cloudbased services at HEIs, staff, faculty, and students can utilize its services to perform various academic responsibilities on demand. This paper aims to adopt CC for HEIs and explore the prominent features and potential benefits of adopting cloud services in the HEIs of KSA. This paper also reveals numerous challenges, impacts, and major issues involved in adopting cloud services for HEIs.
\end{abstract}

Keywords-Cloud computing; higher educational institutions; Cloud Service Provers (CSP); Software-as-a-Service (SaaS); Platform-as-a-Service (PaaS); Infrastructure-as-a-Service (IaaS)

\section{INTRODUCTION}

In recent years, $\mathrm{CC}$ has emerged as a promising paradigm and received significant attention from many industries. CC is growing very fast and being adopted by many business domains in the world. According to the recent Gartner, Inc. report $^{1}$, the significant changes in the cloud market have been noticed. The worldwide public cloud market projected to grow very fast as compared to the previous years. It is predicted that the global cloud market is projected to grow from \$ 182.4 in 2018 to $\$ 331.2$ billion in the year 2022 . The compound annual projected growth of the cloud market prediction is $18.42 \%$, which indicates significant changes in the coming years. Fig. 1 summarizes the "worldwide public cloud service revenue forecast" for PaaS, SaaS, and IaaS.

Recently, CC has sparked a revolution in higher education and has attained a major role in providing HEIs services. With its new promising benefits, CC enables all its HEIs stakeholders including students, academic staff, administrative staff, and other key stakeholders to access services that are hosted on cloud (SaaS, PaaS, IaaS) [1],[2] on demand. Nowadays, HEIs in many countries have started to implement cloud models. There are 3-types of cloud models (Private, Government, and Third-Party Clouds). Some universities in the world started to implement a private cloud, which have to establish self-owned cloud [3], some Universities use government-owned shared clouds [4], and some Universities buy and avail third-party vendors [5] cloud services.

This paper aims to identify and explore the promising benefits and challenges of CC adoption at HEIs in the KSA. The author explores major promising benefits including costeffectiveness, high capability, greater flexibility, 24/7 accessibility, openness, boost collaborative work, accountability, great opportunities with a variety of choices in teaching, learning, management, and challenges including security, integrity, availability, improper management, training for staff, complexity, and affordability. The author also discusses the current state of the cloud adoption at HEIs in KSA. This research will help to motivate the HEIs of KSA to adopt cloud-based services for sustainable development and to achieve one of its promising goal of KSA Vision 2030.

The remainder of this paper organized as follows. Section II describes CC, its characteristics, and CC at HEIs. Section III describes stages in the adoption of CC services at HEIs. Section IV discusses the present state of cloud adoption of KSA Universities. Section V explores the CC adoption advantages, issues, and challenges at HEIs. Finally, Section VI concludes the paper.

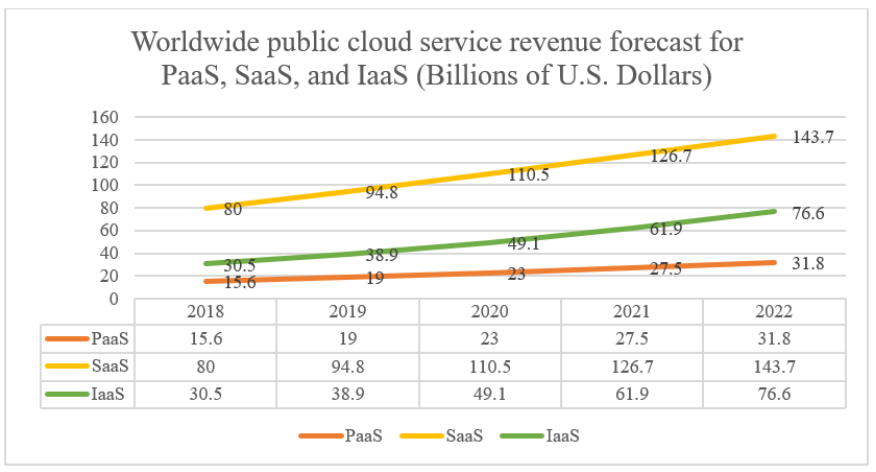

Fig. 1. Worldwide Public cloud Service Prediction (Source: Gartner Inc, April 2019).

\footnotetext{
${ }^{1}$ https://www.gartner.com/en/newsroom/press-releases/2019-04-02gartner-forecasts-worldwide-public-cloud-revenue-to-g
} 


\section{Cloud COMPUTING}

$\mathrm{CC}$ is an idea of combining technological resources online. This term first introduced by Google in 2006 and has become the standard in the modern days computing environment. The online resources (Networks, servers, storage, and applications, etc.) can put in the common pool where any individual or company can pay-per-use the series of services according to their specific needs with minimal management efforts. Cloud leverages several elements including scale, cost-efficiency, resilience, service orientation, agility, etc. This pay-per-use feature of cloud models enables the user to access the resources as per their requirement from the shared-pool online resources available on the network. The end-user can access resources $24 / 7$ from anywhere using various types of devices such as laptops, desktop, and smartphone. The platforms (System Software) and infrastructure (Hardware) used to execute various application software which user access and use online on-demand (Fig. 2).

According to the NIST CC definition [25], there are "five essential characteristics", "three service models", and "four deployment models" as given in Fig. 3.

$\mathrm{CC}$ definition models are interrelated and work together to perform the desired task as per its characteristics. CC definition model is shown in Fig. 3 and demonstrates how each of the five essential characteristics of $\mathrm{CC}$ is encompassed as an integral part of each cloud service model (IaaS, PaaS, and $\mathrm{SaaS}$ ). According to the definition determined by the NIST [25] to provide an IaaS, PaaS, and SaaS solution for cloud services. These include all five characteristics of CC. If it does not satisfy any one of the characteristics, then it is not offering real cloud service as per NIST definition [25]. The creation of four-cloud deployment models (Private, Public, and Community clouds) is the result of integrating any one or more service models.

\section{A. CC Characteristics}

$\mathrm{CC}$ is different from outsourcing software services. It has five key characteristics that distinguish from outsourcing software services [6]. These characteristics of CC are given in Fig. 4.

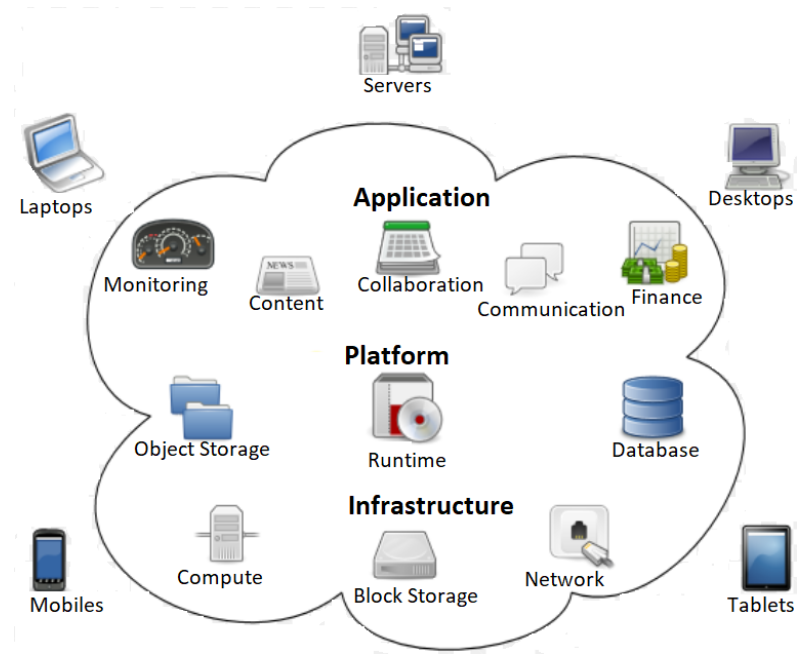

Fig. 2. Cloud Computing.

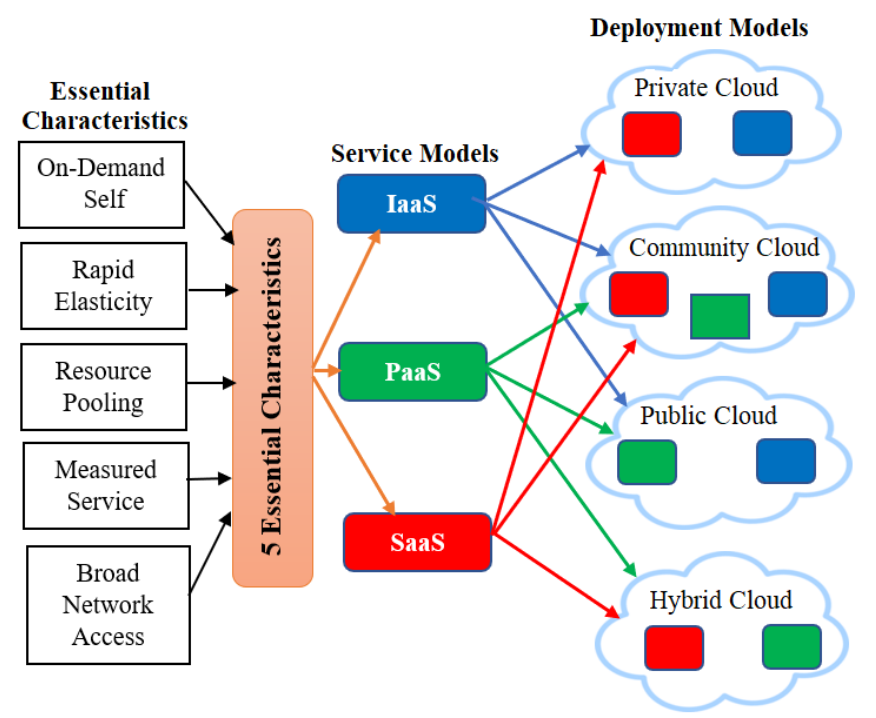

Fig. 3. NIST CC Definition Models [25].

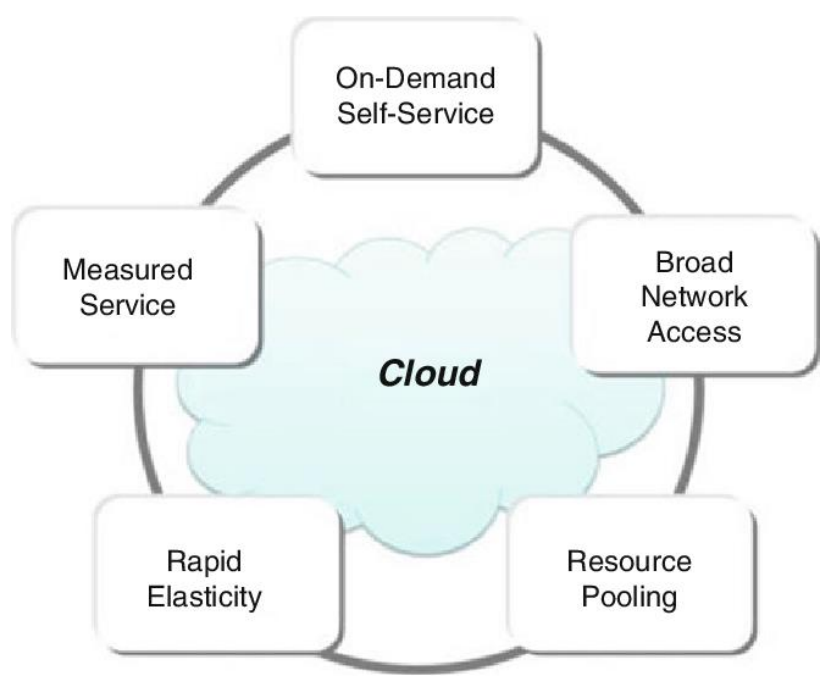

Fig. 4. Five Key Characteristics of CC [6].

These characteristics can be utilized by HEIs as follows:

1) Broad Network Access: Stakeholders of HEIs such as students, academic staff, and other key stakeholders can access network resources by using various devices.

2) Measured Service: This service allows the HEIs key stakeholders to automatically control and improve the use of resources by introducing measured services which can be later modified as per the requirement of HEIs. The key characteristic of this feature is to provide an efficient, fruitful, and cost-effective service. This enables HEIs stakeholders to use the cloud services "as pay and use service" without wasting money on downtime.

3) On-demand Self-Service: This service allows the HEIs stakeholders to access a variety of resources (email, storage, and applications, etc.) from anywhere at any time.

4) Rapid Elasticity: This service enables the HEIs stakeholders to process, utilize and adjust the cloud resources to meet the requirements according to their demand. 
5) Resource Pooling: the main objective of this service is to enable the HEIs stakeholders to use pooled cloud resources via networks according to their demands.

The aforementioned characteristics related to the major advantages of cloud services in regards to HEIs, which motivate to adopt CC for efficient, fruitful, cost-effective services. Cloud services permit HEIs to develop cost-effective and quality education at a global level. Shyan [7], studied cloud services and found that we cannot give financial justification when one is dependent on an individual machine to fulfill the computing requirements. Seigle [8], found that combining the various IT services to justify the quality of service and efficient nature of the cloud. The advancements of modern technologies, cost-reduction, flexibility, and quality aspects of the cloud are a clear justification for the CC adoption by HEIs [2], [9]. Therefore, CC comprehends a paradigm shift for ICT advancement in HEIs.

\section{B. CC at HEIs}

HEIs play a vital role in building better societies. The education field has always incorporated new technologies and teaching methodologies towards educational empowerment. Over the years, most of the HEIs in the world are becoming extremely dependent on modern ICT in terms of fulfilling their service requirements for content delivery, management, communications, and collaboration. These services are increasing very fast. These services provided using high-speed internet and web browsers access to the HEIs key stakeholders including faculty members, students, administrative staff, and other members.

In the traditional system, HEIs requires to spend huge costs for the ICT infrastructure. It also requires having a highly skilled IT Department and many demanding software solutions. It requires spending lots of time and money. Over the last two decades, $\mathrm{CC}$ has empowered HEIs to offer a variety of on-demand cost-effective services efficiently. These cost-effective services are used by HEIs key stakeholders to support learning, accessing online classes, online class registration, social interaction, content creation, course design, and class preparation daily. For example, cloud-based services include OneDrive, Dropbox, and Google Apps, Social media such as Facebook, YouTube, and Twitter. HEIs cloud can provide a variety of services as shown in Fig. 5.

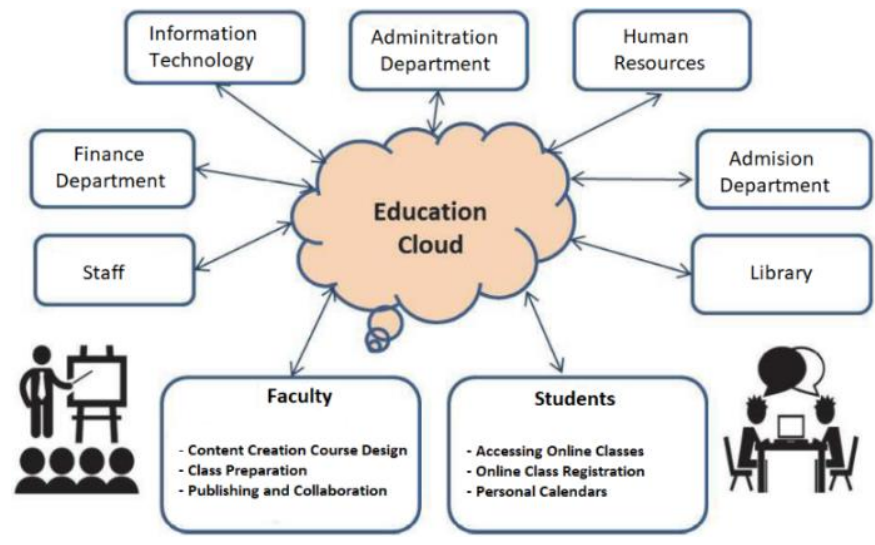

Fig. 5. Cloud and its Services at HEIs.
TABLE I. COMmon Cloud Service Model ANd Key USERS AT HEIs.

\begin{tabular}{|c|c|c|}
\hline $\begin{array}{l}\text { Service } \\
\text { Models }\end{array}$ & Descriptions & Key Users \\
\hline SaaS & $\begin{array}{l}\text { SaaS entirely depends on the internet where } \\
\text { applications are deployed and available on- } \\
\text { demand. End-users can access applications } \\
\text { using the browser or by using an interface. } \\
\text { Subsequently, application services offered to the } \\
\text { end-user on-demand through software. This } \\
\text { feature enabled end-user to deploy the services } \\
\text { quickly, which brings ease of use and monetary } \\
\text { benefits. Many CSP corporations in the world } \\
\text { offering these types of platforms such as } \\
\text { GoogleApps (email, google docs, and calendar), } \\
\text { Salesforce, NetApp, ServiceNow, and } \\
\text { GotoMeeting. }\end{array}$ & $\begin{array}{l}\text { Faculty, } \\
\text { Staff, } \\
\text { Students, } \\
\text { classes and } \\
\text { Admin } \\
\text { Department }\end{array}$ \\
\hline IaaS & $\begin{array}{l}\text { This is a virtual platform that allows end-users } \\
\text { to deploy their applications on cloud } \\
\text { infrastructure and use services such as } \\
\text { networking, storage, database, backup, security, } \\
\text { and other resources. This platform gives full } \\
\text { control to the user over operating systems and } \\
\text { deployed applications. Many companies in the } \\
\text { world provide these types of platforms such as } \\
\text { AWS, Rackspace, AttendaRTI, Amazon EC2, } \\
\text { and CenturyLink }\end{array}$ & $\begin{array}{l}\text { Servers, } \\
\text { Data } \\
\text { Storage, IT } \\
\text { Department, } \\
\text { and } \\
\text { Researchers }\end{array}$ \\
\hline $\mathrm{PaaS}$ & $\begin{array}{l}\text { This is a platform-based service having a suite } \\
\text { of cloud services that provides end-users to } \\
\text { develop, execute, manage, and integrate on- } \\
\text { premises and cloud-based applications and } \\
\text { services. This feature offers no waiting time } \\
\text { required for the deployment of appropriate } \\
\text { applications (hardware and software). End-user } \\
\text { can build applications by utilizing the platform } \\
\text { and using the tools, languages, and services } \\
\text { supported by CSP. Many companies in the } \\
\text { world provide these types of platforms such as } \\
\text { GoogleAppEngine, Azzure, AWS, OCP, and } \\
\text { Salesforce. }\end{array}$ & $\begin{array}{l}\text { Execution, } \\
\text { Database, } \\
\text { Researchers, } \\
\text { and } \\
\text { Developers }\end{array}$ \\
\hline
\end{tabular}

Cloud services delivered through different service model structures. Table I [10] summarized the most common cloud service models and their key users at HEIs.

Ali MB et al. [11], have recently reviewed various papers related to cloud adoption in HEIs. Recently, they have studied 20 research papers related to CC adoption in HEIs. From their study, they have examined the major advantages, challenges and several issues towards cloud adoption in HEIs. They confirmed that there is an increasing interest from various HEIs around the globe to migrate to the cloud.

\section{Stages IN THE Adoption OF Cloud SERVICES AT HEIS}

The adoption of cloud services at HEIs requires a welldefined cloud strategy that supports CC capabilities. For a well-defined cloud strategy, there is a need to hire experts from various fields. This will help the administrators to fully understand the benefits of the cloud-based services model, its impact and the major issue of CC adoption. The strategy implementation of cloud services involves creating a new framework that must be built according to the need of key stakeholders such as faculty, students', and board directors of the HEIs. To have a successful cloud strategy, the key stakeholder should primarily participate to define the HEIs cloud strategy that addresses its opportunities, challenges, and 
issues specific to HEIs as well as cloud strategy must be aligned with HEIs strategy. Many HEIs in the world have not been successful in the adoption of cloud service because of the failure of cloud-strategy. Moreover, many HEIs around the globe do not know how to take initiative to start cloud projects.

\section{A. Stage 1 (Identify Cloud Service Requirement)}

This step requires HEIs to intricately study the cloud and achieve a comprehensive analysis of the applications and service requirements. From the software perspective, it also needs to determine the feasibility of the project. The cloud services delivery to the HEIs key stakeholders should be based on their requirements. End-user services are offered ondemand and are billed pay-per-use. The requirements and feasibility study need to be determined in this stage, and a crucial plan to be developed. This stage also elaborates on how the strength and opportunities of the existing system can be maximized and weaknesses and threats can be minimized. Furthermore, this stage will be determining what services are needed and how much services will have to be consumed for the faculty, staff, students and other HEIs key stakeholders.

\section{B. Stage 2 (Evaluation Stage)}

This step needs HEIs to study and analyze the current stage of the IT internal process and its impact on cloud services adoption. This step also elaborates on the experimental use of cloud services, opportunities, challenges, and major issues. The traditional system needs to be reviewed and all the service conveyance needs to be considered. This stage also stressed the demand for refinement of the traditional system and the elimination of inefficient processes. Security, legal issues, and other issues which are identified in stage 1 need to be set. HEIs' finest policies, practices, and how these can be achieved when shifting to the cloud. This stage also considers the broader impacts on HEIs such information and data security protection and supports services. The main objective of this stage is to identify emerging technologies and their efficiency in terms of cost and time [12].

\section{Stage 3(Choosing Solution and Migration)}

This step requires to choose the solution for the actual migration of the systems. End-user should go through in-depth study for the internal IT processes with their offering services to determine the overall architecture of the workload, the security profile for each workload, and its local environment. In this stage system integration needs to be done after the conclusion. In conclusion, the decision should be made for the cloud deployment model. HEIs must decide workload and its platform, run on either public cloud, private cloud or combination of both. Application and data migration can proceed in this stage. Support services should be provided to the end-user during the migration. Monitoring and control for the project needed to ensure a successful migration. All the practices, learning lessons, cost management should be documented and must be communicated to all HEIs key stakeholders. For HEIs, investments in migration to cloudbased services should be based on maximizing the current resources that they already have such as networking, database, and storage. The analysis of the cost-effectiveness, high performance, and network connectivity must also be taken into account. The primary benefits and significant challenges must be stressed in providing short-term and long-term storage in the cloud. Criteria need to be finalized to find out the best cloud solutions that offer scalable, reliable, secure, and flexibility. For example, data security, rapid development, and flexibility for providing facilities in e-Learning and distance education should be focused on.

\section{Present State of Cloud Adoption of KSA UNIVERSITIES}

M. Al-Ruithe et al. [24], recently reviewed the present state of cloud adoption in the public sectors of KSA. From their study they found that the majority of public sectors $(54.37 \%)$ have not adopted cloud-based services in their organizations, $29.13 \%$ adopted some form of cloud-based services, and 16.50 $\%$ don't know about it. To do the measurement of the present state of cloud adoption at HEIs in KSA, the author has followed the same approach. The author has surveyed to make an analysis of the present state of cloud adoption and cost comparison among traditional and cloud-based services at Universities in KSA. Questionnaires were distributed to various Universities in KSA to the members of the various departments including Administrative, Academic, and IT. The questionnaire has been distributed to 90 correspondents, in which 71 responded. The response rate was $78.89 \%$ which is considered a very good response. The first measurement was conducted to find out the cloud adoption with the direct response ("Yes"/ "No"/ "Don't know"). The survey shows that the majority of the Universities in KSA $(52.12 \%)$ still have not adopted cloud services. $16.89 \%$ responded that they "Don't know" and $30.99 \%$ responded that they have already adopted some cloud-based services especially SaaS in their Universities (Fig. 6).

For those who reported with "No", the data has been collected with the direct sub-questions ("intend to adopt in the next 1 year"/ "intend to adopt in the next 2 years"/ "not yet decided"/ "don't know"). 16.22\% reported they "intend to adopt in the next 1 year", $37.84 \%$ reported they "intend to adopt in the next 2 years", $32.43 \%$ reported they have "not yet decided", and $13.51 \%$ reported they "don't know" about it (Fig. 7).

This section described who have already adopted CC models and reported consuming cloud services. SaaS service model adopted by $54.55 \%$, while IaaS adoption rate is 31.82 $\%$ and PaaS adoption rate is $13.63 \%$ (Fig. 8).

The KSA Universities' organizational structure is shown in Fig. 9. As can be seen from the KSA Universities' organizational structure there are many offices including vicerectors', finance, deanships, and colleges working under the Rectors' office. Different universities have various colleges and deanships. On average each University has 13 colleges. The number of departments at colleges also varies from college to college ranging from 4 departments to more.

To make analysis and do the comparison, data was collected in regards to calculating the approximate manual, electronic, and cloud-based services cost. Approximate cost estimation has been summarized in Table II. Due to the confidentiality and secrecy of the organization and department data has been compiled and the actual cost has been hidden. 
Unit approximate cost for the particular offices, colleges, deanship, and others has been considered to do the analysis and comparison. In this study, the author has considered the number of units for Rector's office (1), Rector's Admin offices (5), Vice Rector's offices (4), Vice Rector's Admin offices (3), Colleges (13), and others (10).

From this study, it is confirmed that there will be a $73.97 \%$ cost reduction as compared to the manual cost and $61.65 \%$ cost reduction as compared to electronic cost. The study motivates HEIs to adopt $\mathrm{CC}$ based services due to the enormous cost reduction and prominent benefits. The study also elaborates adopting $\mathrm{CC}$ based services at HEIs in KSA will have great positive impacts. Fig. 10 represents the cost comparison analysis of traditional vs. cloud at KSA Universities.

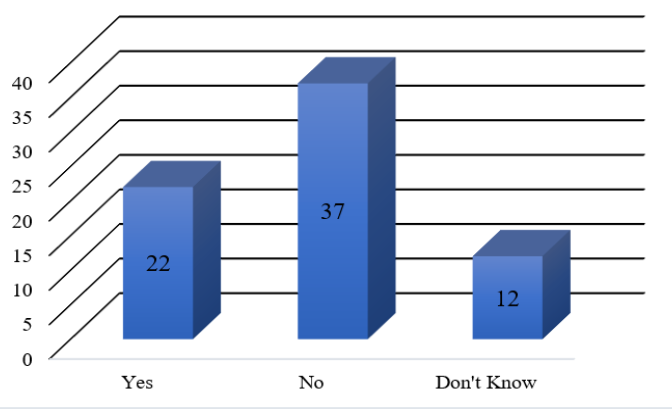

Fig. 6. The Present State of Cloud Adoption at KSA Universities.

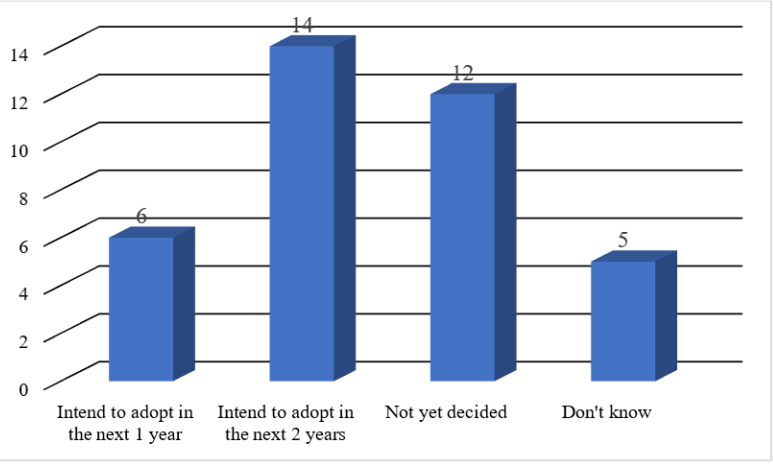

Fig. 7. KSA Universities Plan for cloud Adoption.

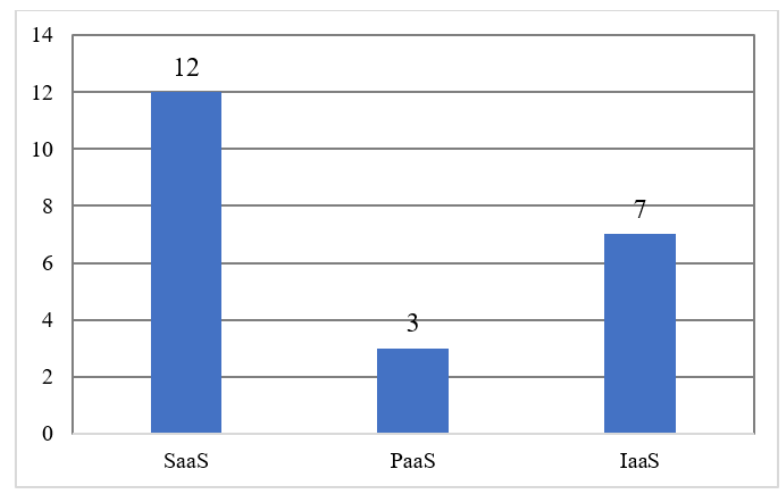

Fig. 8. Cloud Service Model Adopted by KSA Universities.

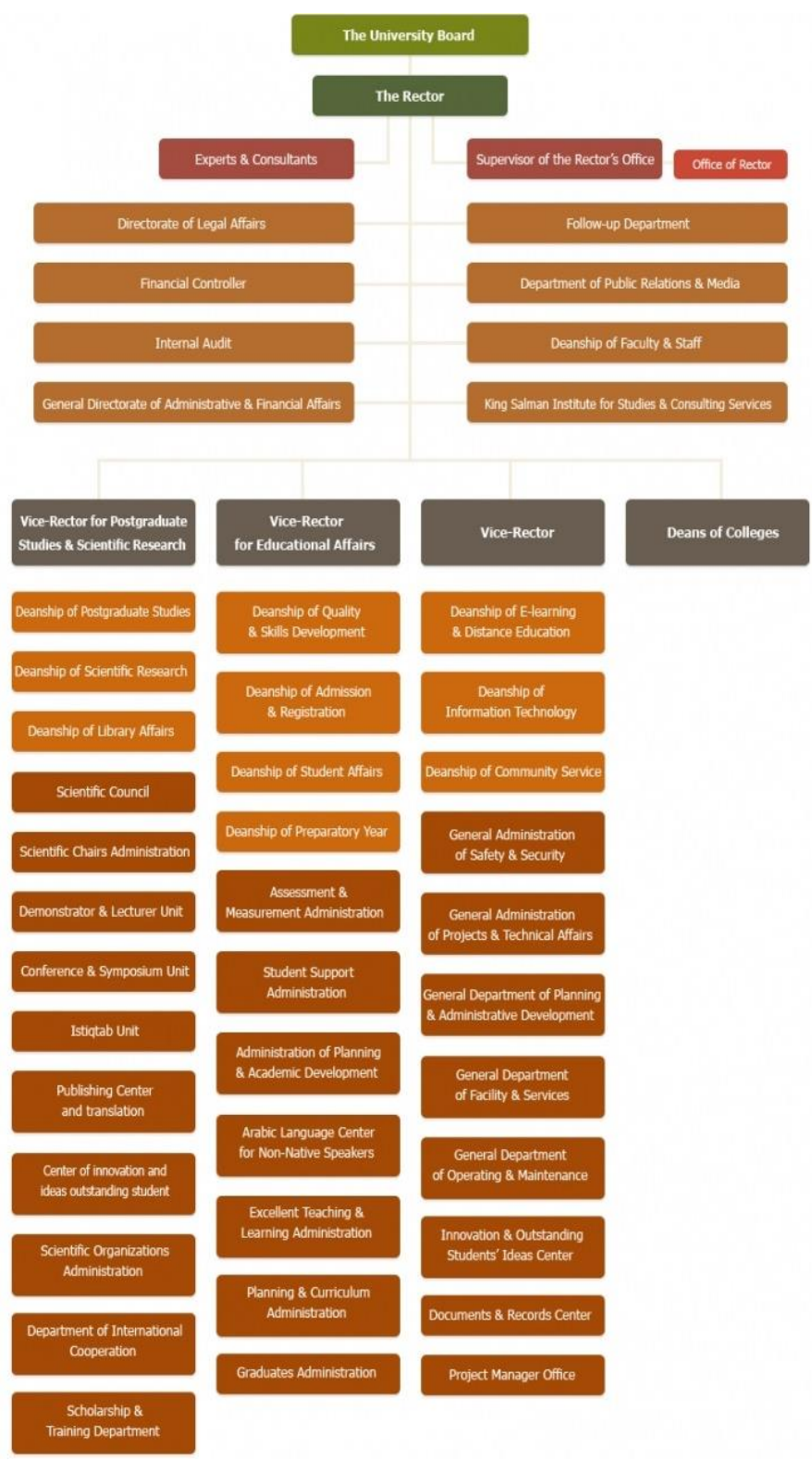

Fig. 9. The Organizational Structure of KSA Universities (Source: Majmaah University, KSA).

TABLE II. APPROXIMATE COST ESTIMATION AMONG MANUAL, ELECTRONIC AND CLOUD-BASED SERVICES

\begin{tabular}{|l|l|l|l|}
\hline University Offices & Manual Cost & $\begin{array}{l}\text { Electronic } \\
\text { Cost }\end{array}$ & $\begin{array}{l}\text { Cloud } \\
\text { Cost }\end{array}$ \\
\hline Rector's office & 12 & 10 & 2 \\
\hline Rector's Admin Offices & 25 & 15 & 5 \\
\hline Vice Rector's offices & 16 & 8 & 4 \\
\hline $\begin{array}{l}\text { Vice Rector's Admin } \\
\text { Offices }\end{array}$ & 30 & 21 & 6 \\
\hline Colleges & 39 & 26 & 13 \\
\hline Deanship's & 44 & 33 & 11 \\
\hline Others & 30 & 20 & 10 \\
\hline
\end{tabular}




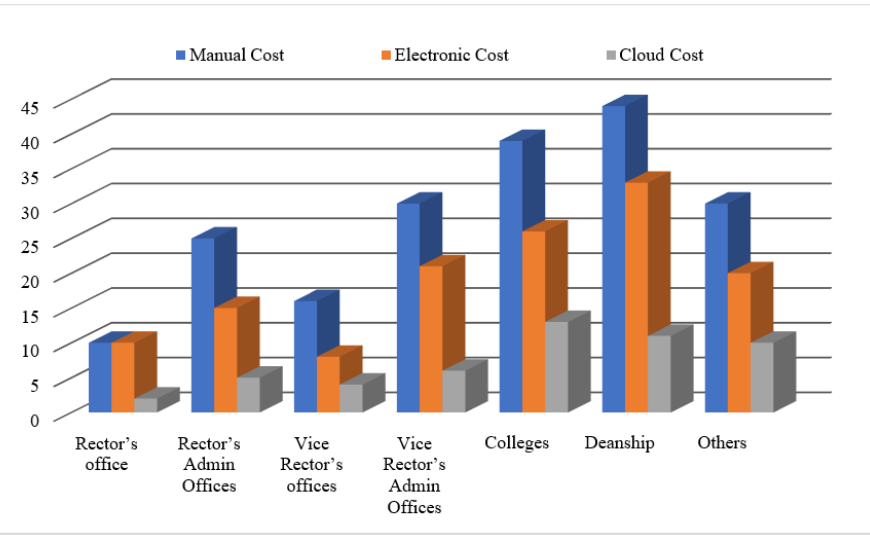

Fig. 10. Traditional Vs. Cloud cost comparison at KSA Universities.

\section{CC ADOPTION AdVANTAGES, ISSUES, AND CHALLENGES AT HEIS}

The major objective of adopting CC at HEIs is to save both time and money. $\mathrm{CC}$ can eradicate the requirement of various specialized software and hardware on individual faculty or departments of the HEIs. This, in turn, allows for a greater degree of flexibility to access and scales various hardware and software resources. Any individual member or department will be able to access the required information stored on the "Cloud" from anywhere they have access to the internet. This will allow every individual to access and submit their information from anywhere at any time. For example, professors can submit the grade of students while they are out of the office and students to be able to access their assignments, lecture notes and emails during the semester breaks. Over the years, several researchers described many benefits of CC in HEIs. CC generally employed in HEIs for a student information system (SIS) and Learning Management Systems (LMS) [13]-[16].

CC adoption at HEIs will have a great impact on the reduction of capital investment in software and hardware infrastructure [11], [14]. Over the years many researchers have explored promising benefits of cloud-based services such as cost-effectiveness, greater flexibility, utilization of resources, rapid development, easy maintenance, and increased scalability, enhance availability, [2], [11], [14], [17]-[19],[23]. Cloud-based services provide great opportunities for HEIs key stakeholders with a variety of choices in teaching, learning, and management. This enables faculty, students, and staff to use many applications free of cost, or pay-per-use. These features also enable HEIs to focus more on their research and teaching goals. Cloud-based services offer openness to students and other stakeholders to use new technologies. Cloud-based services also offer more flexibility to faculty, students, and staff to acquire resources and use services on-demand. Cloudbased services boost collaborative work, which enables students, faculty, and staff to access resources and applications on-demand from their computers without the installment of specific software. This facility enables flexibility and facilitates interdepartmental collaboration. Every HEIs need to submit Quality Accreditation Report after a specific period. It is a continuous process. To submit the report there is a need to provide lots of evidence for quality accreditation. Cloud-based services improve accountability and enable the HEIs stakeholder to collect a large amount of information just by submitting them into the system without wasting time.

In addition to the promising advantages, cloud-based services include various security issues and challenges in CC adoption at HEIs [2],[11],[20]-[22]. These issues and challenges must be managed for a truly successful paradigm shift for the HEIs. The major issue is the lack of control and ownership of data. In CC, data and information are not stored on-premises of HEIs and data accessed through the internet. The third-party provides these services. It is the responsibility of the HEIs to ensure that it implements all security features to protect information against unauthorized access, modification or destruction of data and information. CSPs must provide appropriate standards to protect the CC system and ensure the confidentiality, availability, and integrity of the system. To ensure these HEIs may require using a strong encryption mechanism, and other security features to protect data and information. In addition to security issues, there are some challenges at HEIs such as improper management, training for the staff, integration, complexity, and affordability. Lack of training to the staff in the implementation or use of the cloud can lead to the inadequate utilization of the cloud. For example, a virtual lab left open and not managed properly will increase the cost irrespective of actual usage. Proper cloud management will have a great impact on effective consumption, operation, and optimization of cloud services. Table III summarizes the advantages, issues, and challenges at HEIs.

TABLE III. CC ADOPTION AdVANTAgES, SECURITy IsSUES AND CHALLENGES AT HEIS

\begin{tabular}{|ll|ll|ll|}
\hline$\checkmark$ & Advantages & $\checkmark$ & Security Issues & HEls Challenges \\
\hline$\checkmark$ & Cost Reduction & & & \\
$\checkmark$ & Access to applications from anywhere & & \\
$\checkmark$ & Centralized Management & & \\
$\checkmark$ & Boost collaborative work & $\checkmark$ & Information Security & \\
$\checkmark$ & Rapid development and increased scalability & $\checkmark$ & Improper Management \\
$\checkmark$ & Easy customization, continuous improvements. & $\checkmark$ & Data privaction & Training for staff & \\
$\checkmark$ & Free software or pay-per-use & $\checkmark$ & Data Sanitization & Integration \\
$\checkmark$ & Support for teaching and learning & $\checkmark$ & Inadequate computers \\
$\checkmark$ & Enhanced 24/7 availability & $\checkmark$ & Unauthorized Access & Poor internal access \\
$\checkmark$ & Reallocation resources and easy maintenance & $\checkmark$ & Culture of HEIs \\
$\checkmark$ & Increased openness of students and other stakeholders to new technologies. & $\checkmark$ & Integrity \& Availability & & Complexity and Affordability \\
$\checkmark$ & Improves accountability and automatic provisioning & & & \\
$\checkmark$ & Increased utilization through sharing of the resources & & \\
$\checkmark$ & More flexibility: acquire resources and use services on-demand & & & \\
\hline
\end{tabular}




\section{CONCLUSION}

The KSA government "Cloud First" policy ${ }^{2}$ is an effective initiative in the reforming process to achieve the goal of its promising KSA vision 2030 under the e-University theme. CC is now a mainstream paradigm of IT services that recognized as a massive benefit to HEIs. In recent years, cloud usage in HEIs around the globe is common and becoming widely recognized in the field of education. CC enables all its HEIs stakeholders including students, academic staff, administrative staff, and other key stakeholders to access services by using any device anywhere at any time. Many HEIs in the world have already adopted cloud services for SIS and LMS. In this paper, the author explores the promising benefits of cloudbased services including cost-effectiveness, high capability, greater flexibility, 24/7 accessibility, openness, boost collaborative work, accountability, great opportunities with a variety of choices in teaching, learning, and management. All of these are contributing to the rapid acceptance of CC in HEIs for sustainable development. Issues and challenges must be understood, managed for a true paradigm shift for HEIs. Security, integrity, availability, improper management, training for staff, complexity, and affordability are some of the major implementation challenges that need to be taken into account. The author also discusses the present state of cloud adoption at HEIs in KSA. Around 52\% of KSA Universities presently do not adopt cloud services. cloud-based services adoption is a foremost decision for any HEIs. The main contribution of this work is to motivate the HEIs of KSA to adopt cloud-based services for sustainable development and to achieve one of its promising goal of KSA Vision 2030.

\section{ACKNOWLEDGMENT}

The author would like to thank the Deanship of Scientific Research at Majmaah University for supporting this work under project no. R-1441-97.

\section{REFERENCES}

[1] D. Manzoor, A. Ali, and A. Ahmad, "Cloud and Web Technologies:Technical Improvements and Their Implications on EGovernance," International Journal of Advanced Computer Science and Applications, vol. 5, no. 11, pp. 196-201, May 2014.

[2] N. Sultan, " Cloud computing for education: A new dawn?," International Journal of Information Management, vol. 30, no. 2, pp.109-116. April 2010.

[3] HE. Schaffer et. al., "NCSU's virtual computing lab: A cloud computing solution," Computer, vol. 42, no. 7, pp. 94-97, July 2009.

[4] The determinants of cloud computing adoption by colleges and universities, WE. Klug, USA: Northcentral University, 2014.

[5] AA. Shakeabubakor, E. Sundararajan, and A. R. Hamdan, "Cloud computing services and applications to improve productivity of University researchers," International Journal of Information and Electronics Engineering, vol. 5, no. 2, March 2015.

[6] F. Shahzad, "State-of-the-art survey on cloud computing security Challenges, approaches, and solutions," Procedia Computer Science, vol. 37, January 2014.
[7] J. Shayan et. al., "Identifying Benefits and risks associated with utilizing cloud computing," arXiv preprint arXiv:1401.5155, January 2014.

[8] D. Siegle, "Technology: Cloud Computing: A Free Technology Option to Promote Collaborative Learning," Gifted Child Today, vol. 33, no. 4, pp. 41-45, October 2010.

[9] N. Sultan, "Reaching for the cloud: How SMEs can manage," International journal of information management, vol. 31, no. 3, pp. 272278, June 2011.

[10] R. Matsumoto, "SaaS does not necessarily equal cloud," http://www.rickmatsumoto.com/saas-does-not-necessarily-equal-cloud/, 2012.

[11] MB. Ali, H. T.Wood, and M. Mohamad, "Benefits and challenges of cloud computing adoption and usage in higher education: a systematic literature review," International Journal of Enterprise Information Systems, vol. 14, no. 4, pp. 64-77, October 2018.

[12] C. Erenben, "Cloud computing: the economic imperative," ESchool News, vol. 12, no. 3, pp. 9-13, March 2009.

[13] AS. Noor, M. Younas, and M. Arshad, "A review on cloud-based knowledge management in higher education institutions," International Journal of Electrical and Computer Engineering, vol. 9, pp. 2088-8708, December 2019.

[14] M. Attaran, S. Attaran, and B. G. Celik, "Promises and challenges of cloud computing in higher education: a practical guide for implementation,"Journal of Higher Education Theory and Practice, vol. 17, no. 6, November 2017.

[15] A. Lin, and NC. Chen, "Cloud computing as an innovation: Perception, attitude, and adoption," International Journal of Information Management, vol 32, no. 6, pp. 533-540, December 2012.

[16] C. Boja, P. Pocatilu, and C. Toma, "The economics of cloud computing on educational services," Procedia-Social and Behavioral Sciences, vol. 93, pp. 1050-1054, October 2013.

[17] KE. Krelja, J. Tomljanovi?, and K. Broni?, "Usage of cloud applications by students," Zbornik VeleuiliŽta u Rijeci, vol. 2, no. 1, pp. 13-26, July 2014.

[18] J. Scholten, "The determinants of cloud computing adoption in The Netherlands: a TOE-perspective," Master's thesis, University of Twente, 2017.

[19] C. Stergiou et. al., "Secure integration of IoT and cloud computing," Future Generation Computer Systems, vol. 78, pp. 964-975, January 2018.

[20] A. Haider A, "Business technologies in contemporary organizations: adoption, assimilation, and institutionalization: adoption, assimilation, and institutionalization," IGI Global, October 2014.

[21] MT. Amron, R. Ibrahim, and S. Chuprat, "A Review on Cloud Computing Acceptance Factors," Procedia Computer Science, vol. 124, pp. 639-646, January 2017.

[22] A. Alharthi et. al., "An overview of cloud services adoption challenges in higher education institutions," pp. 102-109, 2015.

[23] ZM. Jawad, IK. Ajlan, ZD. Abdulameer, "Cloud Computing Adoption by Higher Education Institutions of Iraq: An Empirical Study," Journal of Education College Wasit University, vol. 1, no. 28, pp. 591-608 August 2017.

[24] M. Al-Ruithe, E. Benkhelifa, and K. Hameed, "Current State of Cloud Computing Adoption-An Empirical Study in Major Public Sector Organizations of Saudi Arabia (KSA)," Procedia Computer Science, no. 110, pp. 378-85, Jan 2017.

[25] M. Peter, and T. Grance, "The NIST definition of cloud computing", 2011. pdf

${ }^{2}$ https://www.mcit.gov.sa/sites/default/files/ksa_cloud_first_policy_en. 